\title{
Incidence of asthma and mortality in a cohort of young adults: a
} 7-year prospective study

\author{
Roberto de Marco ${ }^{* 1}$, Francesca Locatelli ${ }^{1}$, Lucia Cazzoletti ${ }^{1}$, \\ Massimilian Bugianio ${ }^{2}$, Aurelia Carosso ${ }^{2}$ and Alessandra Marinoni ${ }^{3}$
}

\author{
Address: ${ }^{1}$ Unit of Epidemiology and Medical Statistics, University of Verona, Verona, Italy, ${ }^{2}$ National Health Service, CPA-ASL 4 Unit of Respiratory \\ Medicine, Turin, Italy and ${ }^{3}$ Department of Applied Health Sciences, University of Pavia, Pavia, Italy \\ Email: Roberto de Marco* - roberto.demarco@univr.it; Francesca Locatelli - francesca.locatelli@univr.it; \\ Lucia Cazzoletti - lucia.cazzoletti@univr.it; Massimilian Bugianio - maxbugiani@libero.it; Aurelia Carosso - acarosso@qubisoft.it; \\ Alessandra Marinoni - alessandra.marinoni@unipv.it \\ * Corresponding author
}

Published: 16 August 2005

Respiratory Research 2005, 6:95 doi:10.1 I86/1465-992I-6-95

This article is available from: http://respiratory-research.com/content/6/1/95

(c) 2005 Roberto et al; licensee BioMed Central Ltd.

This is an Open Access article distributed under the terms of the Creative Commons Attribution License (http://creativecommons.org/licenses/by/2.0), which permits unrestricted use, distribution, and reproduction in any medium, provided the original work is properly cited.
Received: 28 June 2005

Accepted: 16 August 2005

\begin{abstract}
Background: Few longitudinal data exist on the incidence of asthma in young adults and on the overall mortality risk due to asthma. A 7-year follow-up prospective study was performed to assess the incidence of asthma and mortality from all causes in a cohort of young adults.

Methods: The life status of a cohort of 603I subjects, aged 20-44 years, who replied to a respiratory screening questionnaire between 1991 and 1992, was ascertained in 1999. A new questionnaire investigating the history of asthma was subsequently sent to the 5236 subjects who were still alive and residents in the areas of the study. 3880 subjects $(74 \%)$ replied to the second questionnaire.
\end{abstract}

Results: The incidence of adult-onset asthma was 15.3/I0,000/year (95\% Cl:II.2-20.8). The presence of asthma-like symptoms (IRR:4.17; 95\%Cl:2.20-7.87) and allergic rhinitis (IRR:3.30; $95 \% \mathrm{Cl}: \mathrm{I.7I}-6.36)$ at baseline were independent predictors of the onset of asthma, which was more frequent in women (IRR:2.32; 95\% Cl:I.16-4.67) and increased in the younger generations.

The subjects who reported asthma attacks or nocturnal asthma symptoms at baseline had an excess mortality risk from all causes (SMR $=2.05 ; 95 \% \mathrm{Cl}: \mathrm{I} .06-3.58)$ in the subsequent seven years. The excess mortality was mainly due to causes not related to respiratory diseases.

Conclusion: Asthma occurrence is a relevant public health problem even in young adults. The likelihood of developing adult onset asthma is significantly higher in people suffering from allergic rhinitis, in women and in more recent generations. The presence of asthma attacks and nocturnal symptoms seems to be associated with a potential excess risk of all causes mortality.

\section{Introduction}

Asthma is usually considered to be a chronic disease that starts in childhood, characterised by a low specific mortality risk, which can be completely avoidable with adequate management. However, recent epidemiological studies have pointed out [1] that a non negligible number of the current asthmatics in the general population developed 
the disease in adulthood and that adult-onset asthma has a worse prognosis than childhood asthma.

Unfortunately, few longitudinal data exist on the incidence of asthma in adults [2-4]. Consequently, knowledge of the natural history and the risk factors for adult asthma is limited and relies almost completely on prevalence data, which depend on both the incidence and the persistence of the disease. There are even fewer longitudinal studies investigating the outcome of adult asthma in terms of overall mortality [5-9], which suggest that asthma and asthma symptoms are associated with a significantly higher all-causes mortality compared to the general population.

In this paper we describe the incidence of asthma and allcauses mortality in a large, representative sample of young Italian adults, who participated in the European Respiratory Health Survey (ECRHS) stage I in 1991, and who were followed up in 1999/2000. In particular, our objective was to assess the incidence of adult onset asthma and to test : 1) whether a previous history of allergic rhinitis was a predictor for the onset of asthma, after adjusting for known risk factors; 2) whether a previous history of asthma attacks or nocturnal asthma-like symptoms was associated with a subsequent overall mortality excess in young adults.

\section{Methods}

\section{i) Study design}

A repeated survey of those who replied to the screening questionnaire [10] in the frame of the Italian branch of the ECRHS-stage1 in 1991/1992, was performed in three Italian centres (Verona, Pavia and Turin) during 1999/ 2000. The initial cohort was made up of 6031 subjects, randomly chosen from the general population. The mean age of the cohort in 1991/1992 was 32.7 years (range 2044 years) and the percentage of women was $49.6 \%$. All subjects were mailed a new questionnaire up to two times, in case of non response. The questionnaire administered in 1999/2000 included the same standard questions used in the first survey (enquiring about asthma attacks, wheezing, nocturnal dyspnoea, nocturnal tightness, allergic rhinitis in the last 12 months and current use of asthma drugs) with additional questions on the history of asthma (doctor diagnosis, age of the first/ last attack), the history of exposure to active smoking and social class. The questions used in the first and second surveys have been published elsewhere [11].

After the second postal wave, the life and residence status of all non responders to the mail survey were obtained from vital statistics records. Then all subjects who had neither moved nor died before or during the survey were sent a third postal wave and were finally interviewed by phone.
At the end of follow-up, 748 (12.4\%) subjects had moved and $47(0.8 \%)$ died before or during the study; 352 $(5.8 \%)$ could not be traced through anagraphic records, $1004(16.6 \%)$ did not reply or explicitly refused to answer the questionnaire and 3880 (64.3\%) replied.

The protocol of the study was approved by the Italian Ethical Committees of the participating centres, and the individual information was collected in compliance with the Italian law $\left(n^{\circ} 675 / 1996\right)$ concerning the protection of the privacy of individual health data.

\section{ii) Incidence analysis}

$5236(86.4 \%)$ subjects from the initial cohort were considered eligible for this analysis (anyone who had moved or died was excluded). Of these, 3880 replied to the second questionnaire in 1999/2000 (response rate 74\%); 24 subjects were excluded because of the mismatching of age and/or sex. The population at risk for the incidence analysis included all the asthma-free subjects in the first study (1991/92). Accordingly, 302 out of 3856 valid respondents were excluded because they were considered asthmatics at baseline: that is, people who reported having current asthma in the first study (having had an attack of asthma in the last 12 months or currently taking any medicine for asthma) as well as those who, in the second study, reported having had the first asthma attack more than 3 years before the first survey. This was done considering that a discrepancy of less than three years could be due to recall bias when reporting the age of onset (Pattaro C. Long-term repeatability of a questionnaire for lifelong asthma assessment.Personal communication). New cases of asthma were considered those, among the population at risk, who gave a positive answer to the question "Have you ever had asthma?" in the second survey.

Incidence rates were computed by dividing the number of new cases by the total number of person-years. PY was computed as the time between the first and second survey for non asthmatics and the time between the first interview and the first asthma attack for new asthmatics. For 6 subjects, who reported in the second survey having had the first attack of asthma less than 3 years before the first survey, the time at risk was set at 1 day [4].

Subjects, reporting in the first study, having had 'wheezing or whistling in their chest at any time' and/or having 'woken up with a feeling of tightness in the chest' and/or having 'woken up with an attack of shortness of breath' in the past 12 months, were considered as having asthma symptoms at baseline.

All subjects who reported never having smoked in the second questionnaire were considered non smokers at baseline. Subjects who reported having smoked at one time in 
the second questionnaire were classified as smokers or exsmokers at baseline, according to their answers to the following questions: 'How old were you when you started smoking?' and 'How old were you when you stopped smoking?'.

According to postal codes, each subject was considered a resident either in urban or suburban areas. Areas were classified as suburban when the inhabitants of the municipal district were less than 40,000, urban otherwise. Participants were divided into two social classes based on their profession: low (blue collars/unemployed/retired) and medium/high (manager/white collars/teachers...).

The Poisson regression model [12] was used to assess the association of baseline symptoms and individual characteristics with the incidence of asthma.

Statistical analysis was performed using STATA software [13], release 7.0 (Stata Corp 1997. Stata Statistical Software: release 5.0. Stata Corporation, College Station, TX).

\section{iii) Mortality analysis}

All subjects were considered eligible for this analysis. Mortality rates were computed by dividing the number of deaths during the follow-up by the person-years (PY) at risk [12]. PY were computed as: i) the time between the first and the second survey (follow-up time) for responders to the questionnaire; ii) the average follow-up time for non responders; iii) the time between the first survey and the date of death for deceased people; iv) half follow-up time for subjects who had moved before the second survey or were untraceable (censored alive at mid follow-up). Mortality rates were estimated according to symptoms reported at baseline. Standardised Mortality Ratios (SMR adjusted by age, sex and centre) were used to compare the mortality rates in subjects with and without symptoms at baseline.

The specific cause of death was ascertained using the mortality records of the health districts of the three centres involved in the survey; the underlying cause of death was coded according to the International Classification of Diseases, Ninth Revision. The specific cause of death was not found for one subject who had died outside the health district. As information on smoking habits was missing in the first ECRHS questionnaire, it was not possible to adjust the SMR for this variable. However, to verify the stability of our results, a sensitivity analysis was performed on all the subjects who replied to the second questionnaire (3856) and who had the information on smoking habits. In this subgroup, SMRs adjusted for smoking habits were computed assuming that the 47 deaths were 1) all non smokers; 2) all smokers; 3) had the same smoking distribution of the respondents (random assignment).

\section{Results \\ Incidence}

Subjects who were included in the incidence analysis were found to be slightly older (33.1 vs 32.5 years, $\mathrm{p}<0.05$ ) and there was a greater percentage of women $(51.2 \%$ vs $47.8 \%$, p < 0.005) than non responders to the second questionnaire; however, there was no statistically significant difference in symptoms at baseline (first study) between responders and non responders. The average time of follow-up for the incidence study was 7.72 years. Forty-one new cases of asthma out of 3554 people at risk occurred during the period between the two studies (Table $1)$, and the average annual incidence rate was 15.2/ 10000/year (95\%CI: 11.2-20.7), ranging from 10.1/ $10000 /$ year in the older generation to $22.8 / 10000 /$ year in the younger generation. The incidence rate for asthma was greater in women (Figure 1) than men, higher in the younger groups and in urban than suburban areas, lower in active smokers than non smokers and peaked in subjects who reported asthma-like symptoms (wheezing and/ or nocturnal dyspnoea and/or nocturnal tightness in the chest) and allergic rhinitis at baseline.

After adjusting for all these factors, the incidence of asthma (Table 2) was significantly and independently associated with sex (Incidence rate ratio, $\mathrm{IRR}=2.32$, 95\%CI:1.16-4.67), the presence of asthma-like symptoms (IRR $=4.17,95 \% \mathrm{CI}: 2.20-7.87$ ) and allergic rhinitis $($ IRR $=3.30,95 \%$ CI: $1.71-6.36)$; it was also significantly lower in smokers than non-smokers (IRR $=0.33$; 95\%CI:0.15-0.73). The incidence of asthma showed a significantly increasing trend $(\mathrm{p}<0.01)$ according to the birth cohort.

\section{Mortality}

Average follow-up time for the mortality study was 7.05 years. Forty-seven subjects from the initial cohort died between 1991 and 2000. The average annual mortality rate was 11.0/10000/year (95\%CI: 8.3-14.7), consistent with the official mortality data for the same age groups and the same areas (Table 3). Mortality rates were particularly high (Table 4) for people reporting having had at least one attack of asthma (32.2/10000/year), nocturnal dyspnoea (30.3/10000/year) and nocturnal tightness (23.5/10000/year). Subjects who reported no respiratory symptoms at baseline had very similar mortality rates to those who reported wheezing, allergic rhinitis or nocturnal cough.

The reporting of asthma attacks and/or nocturnal dyspnoea and/or nocturnal tightness in the first survey (1991/ 92) was associated with a two-fold increase in subsequent overall mortality (SMR $=2.05 ; 95 \% \mathrm{CI}: 1.06-3.58)$ compared to the rest of the population, after adjusting for age, sex and centre (Table 5). The increase in overall mortality 
Table I: Number of subjects at risk at start of follow-up (199 I/92), number of new cases of asthma, person-years, crude incidence (95\% C.I.) during the period 199I-2000 according to sex and birth cohort.

\begin{tabular}{|c|c|c|c|c|}
\hline & $\mathrm{N}^{\circ}$ of subjects at risk & $N^{\circ}$ of new cases $(199 \mid-2000)$ & Person-years & Incidence* 10,000 \\
\hline Total & 3554 & 41 & 26881 & $15.25(11.23-20.71)$ \\
\hline \multicolumn{5}{|l|}{ Sex } \\
\hline Men & 1720 & 12 & 13040 & $9.20(5.23-16.20)$ \\
\hline Women & 1834 & 29 & |384| & $20.95(14.56-30.15)$ \\
\hline \multicolumn{5}{|l|}{ Birth Cohort } \\
\hline$|946-195|$ & 793 & 6 & 5935 & $10.11(4.54-22.50)$ \\
\hline $195 \mid-1956$ & 738 & 6 & 5634 & $10.65(4.78-23.7 I)$ \\
\hline$|956-196|$ & 710 & 9 & 5379 & $16.73(8.70-32.15)$ \\
\hline $1961-1966$ & 732 & 10 & 5543 & $18.04(9.71-33.52)$ \\
\hline$|966-197|$ & 581 & 10 & 4389 & $22.78(12.26-42.34)$ \\
\hline
\end{tabular}

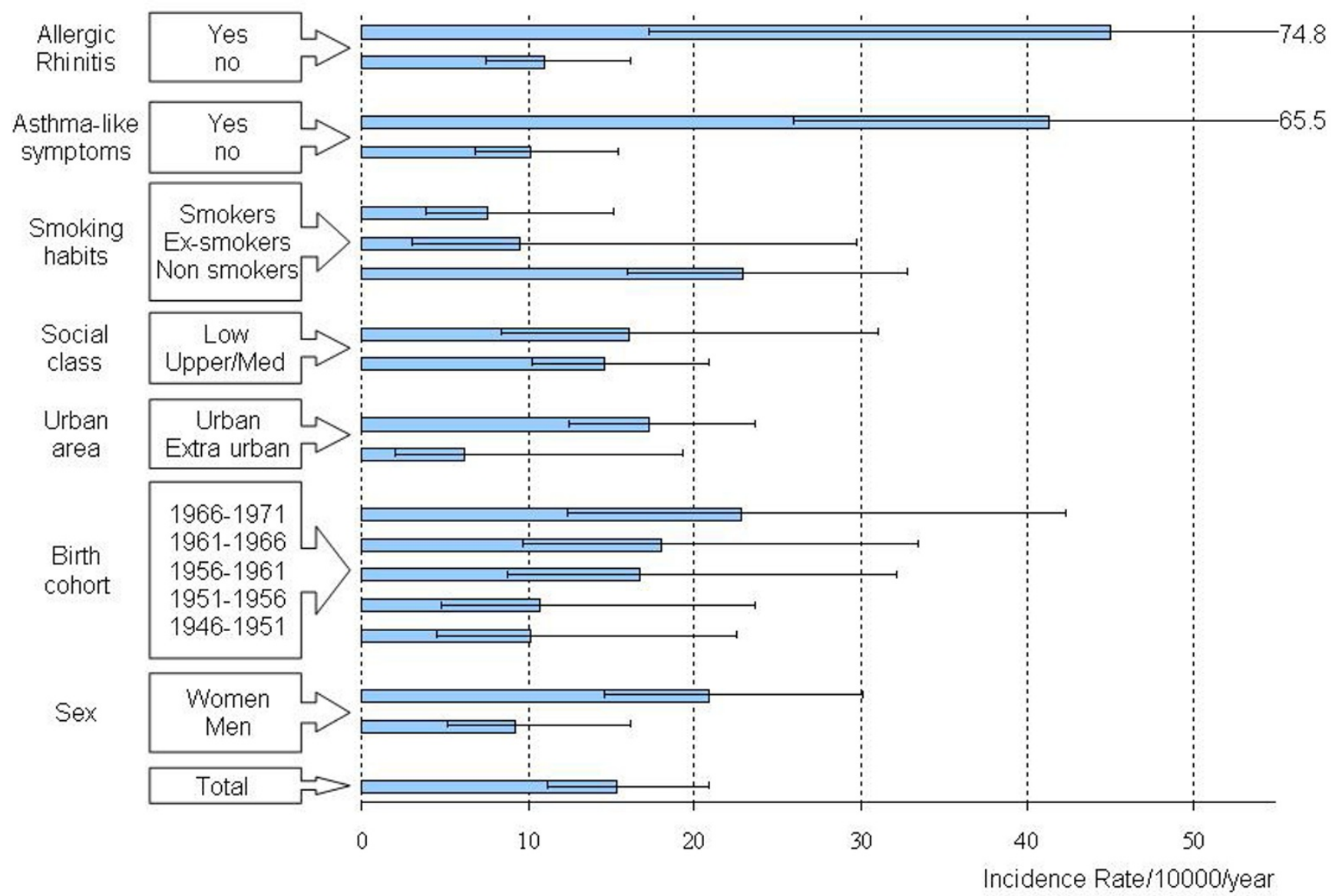

Figure I

Average annual incidence of asthma (*10,000/year) and $95 \%$ confidence interval during the period $1991-2000$, according to baseline characteristics (reported in the first study: $1991 / 1992$ ). 
Table 2: Mutually Adjusted Incidence Rate Ratios (95\% C.I.) for the association of the incidence of asthma with the main baseline characteristics (199//1992).

\begin{tabular}{|c|c|c|c|}
\hline & Relative risk (IRR) & 95\% C.I. & p-value \\
\hline \multicolumn{4}{|l|}{ Sex } \\
\hline Men & 1 & & \\
\hline Women & 2.32 & $1.16-4.67$ & 0.017 \\
\hline \multicolumn{4}{|l|}{ Birth cohort * } \\
\hline$|946-195|$ & I & & \\
\hline $1951-1956$ & 1.12 & $0.36-3.49$ & 0.84 \\
\hline $1956-196 \mid$ & 1.69 & $0.60-4.77$ & 0.32 \\
\hline $196 \mid-1976$ & 1.68 & $0.60-4.69$ & 0.32 \\
\hline$|966-197|$ & 2.28 & $0.82-6.34$ & 0.11 \\
\hline \multicolumn{4}{|l|}{ Urban area } \\
\hline Suburban area & I & & \\
\hline Urban area & 2.52 & $0.77-8.19$ & 0.12 \\
\hline \multicolumn{4}{|c|}{ Asthma-like symptoms** } \\
\hline No & I & & \\
\hline Yes & 4.17 & $2.20-7.87$ & $<0.001$ \\
\hline \multicolumn{4}{|l|}{ Allergic rhinitis } \\
\hline No & I & & \\
\hline Yes & 3.30 & $1.71-6.36$ & $<0.001$ \\
\hline \multicolumn{4}{|l|}{ Smoking habits } \\
\hline Non smokers & I & & \\
\hline Ex-smokers & 0.49 & $0.15-1.65$ & 0.25 \\
\hline Smokers & 0.33 & $0.15-0.73$ & $<0.01$ \\
\hline \multicolumn{4}{|l|}{ Social class } \\
\hline Medium /High & 1 & & \\
\hline Low & 1.65 & $0.77-3.52$ & 0.20 \\
\hline
\end{tabular}

* test for trend $\mathrm{p} \leq 0.01$

** wheezing and/or nocturnal shortness of breath and/or nocturnal tightness in the chest

Table 3: Number of deaths, person-years, average annual mortality rates (95\% Confidence Interval) for the ECRHS-Italy cohort (I99 I2000), and official mortality rates in northern Italy.

\begin{tabular}{|c|c|c|c|c|}
\hline & Number of deaths & Person-years & Mortality rate $* 10,000$ (95\% C.I.) & Northern Italy mortality rates $* 10,000 \$$ \\
\hline Total & 47 & 42523 & II.0 (8.3-|4.7) & 10.9 \\
\hline \multicolumn{5}{|l|}{$\underline{\text { Sex }}$} \\
\hline Men & 34 & 21592 & I 5.7 (| |.2-22.0) & 14.7 \\
\hline Women & 13 & 20931 & $6.2(3.6-10.7)$ & 6.9 \\
\hline
\end{tabular}

\$ISTAT (National Institute of statistics) 1998

for this group of subjects was mainly due to a statistically significant increase in mortality from accidents and a moderate increase in mortality from cancer and cardiovascular diseases. No deaths from respiratory diseases were observed in our cohort, while 4 out of 16 deaths from tumours were due to lung cancer ( 1 in the symptomatic group and 3 in the control group). When the one death with unknown cause was attributed to each specific cause of death, the interpretation of the results was the same (see last column of Table 5). 
Table 4: Number of subjects who reported a specific symptom in the first survey (199//1992), number of deaths observed during the follow-up (199I-2000), crude annual mortality rate (*10,000/year), and its $95 \%$ Confidence Interval.

\begin{tabular}{lcccc}
\hline & Number of subjects at risk & Deaths during 199I-2000 & $\begin{array}{c}\text { Annual mortality } \\
\text { rate*10,000 }\end{array}$ & 95\% Confidence Interval \\
\hline No respiratory symptoms & 3225 & 26 & 11.4 & $7.7-16.7$ \\
Wheezing & 600 & 4 & 9.4 & $3.5-25.1$ \\
Allergic rhinitis & 959 & 7 & 10.5 & $5.0-22.1$ \\
Nocturnal Cough & 1771 & 10 & 8.0 & $4.3-14.8$ \\
Nocturnal Tightness & 1771 & 8 & 23.5 & $11.7-46.9$ \\
Nocturnal Dyspnoea & 429 & 9 & 30.3 & $15.8-58.3$ \\
Asthma attacks & 221 & 5 & 32.2 & $13.4-77.3$ \\
\hline
\end{tabular}

Table 5: Number of deaths (1991-2000), average annual mortality rates for overall and specific causes of death in subjects with or without asthma attacks/nocturnal dyspnoea/nocturnal tightness (A/D/T) in the first survey (199//1992) and Standardized Mortality Ratios adjusted for sex, age and centre.

\begin{tabular}{|c|c|c|c|c|c|c|}
\hline & \multicolumn{2}{|c|}{$\begin{array}{l}\text { Subjects without } A / D / T \\
(n=5169)\end{array}$} & \multicolumn{2}{|c|}{$\begin{array}{l}\text { Subjects with } A / D / T \\
(n=862)\end{array}$} & \multirow[b]{2}{*}{$\begin{array}{c}\text { SMR } \\
(95 \% \text { C.I. })^{\$}\end{array}$} & \multirow[b]{2}{*}{$\begin{array}{l}\text { Simulated SMR } \\
(95 \% \text { C.I. })^{\$ \$}\end{array}$} \\
\hline & $\begin{array}{l}\text { Number of } \\
\text { deaths }\end{array}$ & $\begin{array}{l}\text { Crude mortality rate } \\
\quad * 10,000\end{array}$ & $\begin{array}{l}\text { Number of } \\
\text { deaths }\end{array}$ & $\begin{array}{l}\text { Crude mortality rate } \\
\qquad 10,000\end{array}$ & & \\
\hline All causes & 35 & 9.58 & 12 & 19.96 & $2.05(1.06-3.58)$ & $2.05(1.06-3.58)$ \\
\hline All tumours (I40-239) & 12 & 3.29 & 4 & 6.65 & $2.09(0.57-5.36)$ & $\mathrm{I} .80(0.49-4.6 \mathrm{I})$ \\
\hline - Lung cancer (160-165) & 3 & 0.82 & I & 1.66 & $2.01(0.05-11.18)$ & $1.53(0.04-6.52)$ \\
\hline $\begin{array}{l}\text { Cardiovascular diseases } \\
(390-459)\end{array}$ & 4 & 1.10 & I & 1.66 & $1.34(0.03-7.47)$ & $1.11(0.03-6.18)$ \\
\hline Accidents (800-999) & 4 & 1.10 & 4 & 6.65 & $6.95(1.89-17.80)$ & $5.47(1.49-14.01)$ \\
\hline Other causes & 14 & 3.83 & 3 & 4.99 & $1.29(0.27-3.78)$ & I.2I (0.25-3.54) \\
\hline Unknown & I & 0.27 & 0 & 0.0 & 0.00 & \\
\hline
\end{tabular}

$\$$ with respect to subjects without $A / D / T$

\$ SMR was computed attributing the one death with unknown cause to each of the specific causes of death

The sensitivity analysis confirmed the stability of the previous results. In fact, in the subgroup of subjects with smoking information, the SMR not adjusted for smoking was 1.99 (95CI:1.03-3.48) while those adjusted for smoking were: 1.91 assuming that all the deaths were smokers; 2.02 assuming that all the deaths were non smokers and 1.94 when the same distribution of smoking among the responders was assumed.

The mortality rates for subjects with asthma attacks/nocturnal symptoms and reporting to be or not to be under treatment were $14.4 / 10000$ /year (95\% C.I.: 2.0-102.3) and 20.9/10000/year (95\% C.I.: 11.6-37.8), respectively, and were not statistically different $(\mathrm{p}=0.72)$.

\section{Discussion}

Our results provide information about incidence of adult asthma and all causes mortality risk related to asthma in northern Italy, an area with a relatively low prevalence of asthma [14]. The main findings of our longitudinal analysis were as follows:

i) The average incidence of adult onset-asthma in northern Italy is $15.2 / 10,000 /$ year, which ranks in the lower part of the ranges reported in longitudinal studies in other countries. Allergic rhinitis and asthma-like symptoms are strong and independent predictors of adult-onset asthma, which occurs more frequently in women and in recent generations.

ii) The presence of asthma attacks and nocturnal asthma symptoms (tightness and dyspnoea) in young adults is associated with a two-fold increase in the risk of dying in the subsequent seven years, compared to asymptomatic subjects. 


\section{Incidence}

In our analysis of the incidence of asthma, the population at risk and the new cases of the disease were defined according to the occurrence or absence of a relevant clinical event, such as an asthma attack, which is less likely to be influenced by recall bias and more reproducible than the reporting of asthma symptoms $[15,16]$. It has also been reported that, at least in Italy, the large majority (85\%) of subjects who self-reported an attack of asthma had been diagnosed by a doctor [1]. Consequently, it is likely that our definition slightly underestimates the incidence of the disease compared to symptom-based definition [17] on one hand; but then on the other, it guarantees better specificity [18] and stability of our estimates than other definitions.

Our estimate of the average annual incidence of asthma in young adults in Italy was 15.2/10,000/year, ranging from $10.1 / 10,000 /$ year, in the older generations, to $22.8 /$ $10,000 /$ year in the younger generations. Our longitudinal study confirms that adult asthma occurs more frequently in women and in younger generations. The gender difference in the occurrence of asthma has been pointed out in several previous studies $[17,19,20]$ from different countries and it has been attributed mainly to the role of female sex hormones [21]. The reasons for the generalized increase in asthma incidence in the youngest generations are still unknown. Changes in susceptibility to environmental stimuli leading to asthma (hygiene hypothesis) as well as changes in exposure to environmental factors (increase in air pollution) could have contributed to this increase $[22,23]$. Our finding that incidence of asthma is higher in urban than suburban areas support both the previous hypotheses.

The strongest independent predictor of the incidence of asthma was the presence of asthma-like symptoms, such as diurnal wheezing and nocturnal dyspnoea and tightness, in agreement with a recent longitudinal Spanish study [4]. This finding indicates that there is a group of subjects for which the clinical phase of the disease starts with mild symptoms which are probably not recognized as asthma, but which will be diagnosed in the following years when the disease gets worse and the exacerbations are labelled as asthma attacks in the end.

The presence of allergic rhinitis at baseline, regardless of other asthma symptoms, was another strong predictor of asthma. This result concords with other longitudinal studies showing that allergic rhinitis is an independent risk factor for the onset of asthma [24,2].

The association between allergic rhinitis and asthma has been traditionally interpreted as the progression of a common airway disease associated with atopy $[25,26]$. It has also been reported $[24,27,28]$ that rhinitis is a significant risk factor for adult asthma in both atopic and non atopic subjects, suggesting that other mechanisms, besides atopy, should be invoked to explain the observed association $[29,30]$. Our study, based on questionnaire data and not on a measurement of atopy, cannot contribute to highlight this hypotheses. However, the strong association between early allergic rhinitis and onset of asthma in adulthood suggests that earlier treatment of allergic rhinitis symptoms $[31,32]$ could modify the natural evolution of asthma and prevent the development of a more severe disease. Indeed, interventions such immunotherapy [33], pharmacologic therapy [34] and allergens avoidance [35] for allergic rhinitis seem to be effective in preventing complications and the development of asthma [29-31].

In agreement with other longitudinal studies [36,37], we found that active smoking does not increase the risk of asthma in adults, probably because susceptible people simply do not start smoking or quit smoking very quickly. This finding is in contrast with another longitudinal study on adolescents [38], where active smoking was a risk factor for the incidence of asthma. In any case, whether active smoking is a risk factor for the incidence of asthma or whether it is a selection factor (healthy smoker effect) continues to be an open problem.

Finally, in contrast to a recent paper [39] that found an association between asthma prevalence and socioeconomic status, our results do not support that being in a low social class increases the risk of developing asthma. This suggest that previously reported associations, based on prevalence studies, reflect more the association of social class with the severity and/or the persistence of the disease rather than its association with the occurrence of asthma.

\section{Mortality}

To our knowledge, few studies have been published on the overall mortality risks of adults with asthma or asthma-like symptoms. This is one of the few, that prospectively investigated asthma related mortality risk in a large cohort of young adults. We ascertained life status for all subjects still resident $(82 \%)$ in the same areas where they lived in 1991, while we assumed that people who were untraceable or who had moved before the second survey were censored alive halfway through the follow-up. As there are no reasons to expect that censoring could be related to the outcome or presence of asthma symptoms, our estimates of the mortality risk are not biased by potential selection in the initial cohort.

The presence of asthma attacks and/or nocturnal asthma symptoms was associated with an increased mortality risk from all causes $(\mathrm{SMR}=2.05 ; 95 \% \mathrm{CI}: 1.06-3.58)$. Our esti- 
mate of the relative mortality risk for asthmatics agrees with those previously reported, which ranged from 1.5 [9] to 2.4 [5].

Although the excess death due to chronic obstructive diseases accounted for a substantial part of the mortality risk in other studies $[9,5,6]$, in our study it was mainly due to non respiratory causes of death, such as accidents, and to a lesser extent, to cardiovascular diseases and cancer, which concords with a French study [8]. This discrepancy can be explained by the fact that our cohort included much younger individuals than previous studies, and it is well known that young people $<45$ years are at a much lesser risk of dying from chronic diseases than older people.

Death from accidents is the leading cause of death in the general population aged 15-44 years, at least in Italy. Our results showed that asthmatics belonging to this age group had a 5- to 6-fold risk of dying from accidents than the general population; this suggests that a previous history of asthma attacks and nocturnal symptoms made them even more susceptible to this kind of hazard. This could be due to the fact that asthmatic symptoms, especially nocturnal ones, may interfere with diurnal attentiveness, which could cause fatal occupational accidents [40] as well as car accidents [41]. Furthermore, it has been reported that asthma patients have high rates of anxiety disorders and major depression $[42,43]$, which can also make them more prone to accidents. Another aspect to take into consideration is the fact that many asthmatic subjects also take antihistamines for their symptoms [45], which could have a sedative effect [46] and alter their diurnal concentration. However, in our study, no association was found between the use of drugs reported in the first study and subsequent mortality.

The moderate increase in mortality from cardiovascular diseases and cancer has already been reported $[44,9]$ and could reflect the greater susceptibility of asthmatics to traditional risk factors, which could be fully appreciated in cohorts older than ours. No association was found between wheezing at baseline and mortality likely because this symptom alone has either a low specificity for asthma [18] or identifies a very mild form of the disease. Furthermore, nocturnal asthma-like symptoms or asthma attacks could be partially attributable to other diseases like psychiatric illnesses and heart diseases.

As the screening questionnaire used in the first ECRHS study did not include information on smoking habits, it was impossible to adjust for this factor in the mortality analysis. However, the sensitivity analysis carried out on a sizable sample showed that when smoking information was taken into account, the results were very similar, sug- gesting that the failure to adjust for this potential confounder could have biased our results only to a minor extent.

Nevertheless, some caveat in the interpretation of our mortality results should be taken into account due to the relatively short follow-up period (7 years) and the consequent low number of deaths. As a consequence, our analysis cannot establish a definite causal relationship between the presence of severe asthma symptoms and the subsequent overall mortality due to both the observational nature of our survey and the expected low number of deaths. The absence of a specific asthma related risk of death in our young cohort does not weaken our result: in fact, mortality from asthma is completely avoidable in this age group, and no deaths are expected to be found if health services are adequate [47]. Consequently, the suggestion emerging from our study of an increased non specific mortality risk even in young subjects reporting severe asthma symptoms should be considered as a warning signal, indicating that asthma symptoms may involve a more general risk than normally expected, and should at least promote other studies dealing with the overall mortality pattern in asthmatics.

\section{Conclusion}

The incidence of asthma is a relevant public health problem even in young adults. The likelihood of developing adult onset asthma is significantly higher in people suffering from allergic rhinitis and mild asthma-like symptoms, in women and in more recent generations. Furthermore, our results suggest that the presence of asthma attacks and nocturnal symptoms may be associated with an excess risk of all causes mortality. Greater medical attention should be paid to early asthma-like symptoms (particularly nocturnal ones) and allergic rhinitis.

\section{List of Abbreviations}

ECRHS: European Community Respiratory Health Survey

\section{PY: Person-years}

SMR: Standardised Mortality Ratio

IRR: Incidence Rate Ratio

\section{Competing interests}

RdeM has received a reimbursement for travel expenses to the ERS congress by GlaxoSmithKline Italia in 2003 and 2004.

\section{Authors' contributions}

RdM developed the idea for the study and was responsible for the study design. 
FL was responsible for the data management and analysis.

All the authors were responsible for the data collection in local centres and participated in the interpretation and presentation of the results.

\section{All authors read and approved the final manuscript.}

\section{Acknowledgements}

All authors received funding from the Italian Ministry of University and Scientific Research.

RdM, FL, LC were supported by the University of Verona and the Veneto Region;

AM was supported by the National Health Service, AUSL Pavia;

$M B$ and $A C$ were supported by the National Health Service, ASL 4 Turin

All the funds were used during the collection of data. All the other phases, i.e. the study design, the analysis and interpretation of data, the preparation of the manuscript for the submission were completely independent of these funds.

\section{References}

I. de Marco R, Locatelli F, Cerveri I, Bugiani M, Marinoni A, Giammanco $\mathrm{G}$ : Incidence and remission of asthma: a retrospective study on the natural history of asthma. J Allergy Clin Immunol 2002, I 1 0:228-235.

2. Huovinen F, Kaprio J, Laitinen LA, Koskenvuo M: The incidence and prevalence of asthma among adult Finnish men and women of the Finnish Twin Cohort from 1975 to and their relation to hay fever and chronic bronchitis. Chest 1990, I I 5:928-36.

3. Toren $\mathrm{K}$, Hermansson $\mathrm{BA}$ : Incidence rates of adult-onset asthma in relation to age, sex atopy and smoking: a Swedish population based study of 15813 adults. Int J Tuberc Lung Dis 1999, 3:192-97.

4. Basagana X, Sunyer J, Zock JP, Kogevinas M, Urrutias I, Maldonado JA, Almar E, Payo F, Anto JM: Incidence of asthma and its determinants among adults in Spain. Am J Respir Crit Care Med 200I, 164: I133-1137.

5. Ulrik CS, Frederiksen J: Mortality and markers of risk of asthma death among 1075 outpatient with asthma. Chest 1995, 108: $10-15$.

6. Lange $P$, Ulrik $C S$, Vestbo J: Mortality in adults with self reported asthma. Copenaghen City Heart Study Group. Lancet 1996, 347:1285-9.

7. Connolly CK, Mamun M, Alcock SM, Prescott RJ: The Darlington and Northallerton Prospective asthma study: best function predicts mortality during the first 10 years. Respir Med 1998, 92: $1274-80$.

8. Dantzer C, Tessier JF, Nejjari C, Barberger Gateau P, Dartigues JF: Mortality of elderly subjects with self-reported asthma in a French cohort, 1991-1996. Eur J Epidemiol 200 I, I 7:57-63.

9. Huovinen E, Kaprio J, Vesterinen E, Koskenvuo M: Mortality of adults with asthma: a prospective cohort study. Thorax 1997, 52:49-54.

10. de Marco R, Verlato G, Zanolin E, Bugiani M, Drane JW: Nonresponse bias in EC Respiratory Health Survey in Italy. Eur Respir J 1994, 7:2139-45II.

I I. de Marco R, Zanolin ME, Accordini S, Signorelli D, Marinoni A, Bugiani $M$, Lo Cascio V, Woods R, Burney P: A new questionnaire for the repeat of the first stage of the European Respiratory Health Survey: a pilot study. Eur Respir J 1999, 14:1044-8.

12. Breslow NE, Day NE: Statistical methods in Cancer research: The design and analysis of Cohort Studies Volume 2. Lyon France: IARC Scientific; 1980.
13. Stata Corp: Stata Statistical Software release 5.0 Stata Corporation, College Station, TX; 1997.

14. European Community Respiratory Health Survey: Variations in the prevalence of respiratory symptoms, self reported attack of asthma, and use of asthma medication in the European Community Respiratory Health Survey. Eur Respir J 1996, 9:687-695.

15. Burney PG, Laitinen LA, Perdrizet S, Huckauf $H$, Tattersfield AE, Chinn S, Poisson N, Heeren A, Britton JR, Jones T: Validity and repeatability of the IATLD bronchial symptom questionnaire: an international comparison. Eur Respir J 1989, 2:940-945.

16. de Marco R, Campello C, Basso O, Moi P, Verlato E, Zanolin ME: Agreement between self-reported symptoms and clinical interview in the European respiratory Health Survey in Italy [abstract]. Eur Resp J 1993, 6:s499.

17. Strachan DP, Butland BK, Anderson HR: Incidence and prognosis of asthma and wheezing illness from early childhood to age 33 in a national British cohort. BMJ 1996, 3 I 2: I I 95-9.

18. de Marco R, Cerveri I, Bugiani M, Ferrari M, Verlato G: An undetected burden of asthma in Italy: the relationship between clinical and epidemiological diagnosis of asthma. Eur Respir J 1998, I I:599-605.

19. de Marco R, Locatelli F, Sunyer J, Burney P: Differences in incidence of reported asthma related to age in men and women. A retrospective analysis of the data of the European Respiratory Health Survey. Am J Respir Crit Care Med 2000, I 62:68-74.

20. Thomsen SF, Ulrik CS, Kyvik OK, Larsen K, Skadhauge LR, Steffensen I, Backer V: The incidence of asthma in young adults. Chest 2005, 127:1928-1934.

21. Svanes C, Real FG, Gislason T, Jansson C, Jogi R, Norrman E, Nystrom L, Toren K, Omenaas E: Association of asthma and hay fever with irrefular menstruation. Thorax 2005, 60:445-450.

22. Sunyer J, Anto JM, Tobias A, Burney P, for ECRHS: Generational increase of self reported first attack of asthma in fifteen industrialized countries. Eur Respir J I999, |4:885-89|.

23. Braun-Fahrlander C: Environmental exposure to endotoxin and other microbial products and the decrease risk of childhood atopy: evaluating developments since april 2002. Curr Opin Allergy Clin Immunol 2003, 3:325-9.

24. Guerra S, Sherril DL, Martinez Fd, Barbee RA: Rhinitis as an independent risk factor for adult-onset of asthma. J Allergy Clin Immunol 2002, 109:419-425.

25. Sporik R, Holgate ST, Platts-Mill TA, Cogswell J]: Exposure to house dust mite allergen (Der $p I)$ and the development of asthma in childhood. New Engl J Med 1990, 323:502-507.

26. Litonjua A, Sparrow D, Weiss ST, O'Connor GT, Long AA, Ohman $\mathrm{JL}$ : Sensitization to cat allergen is associated with asthma in older man and predicts new onset airway hyperresponsiveness. Am J Respir Crit Care Med I 997, 1 56:23-27.

27. Rusconi F, Galassi C, Corbo GM, Forastiere F, Biggeri A, Ciccone G, Renzoni E: Risk factors for early, persistent and late onset wheezing in young children. SIDRIA Collaborative Group. Am J Respir Crit Care Med 1999, 160:1617-22.

28. Leynaert B, Bousquet J, Neukirch C, Liard R, Neukirch F: Perennial rhinitis: an independent risk factors for asthma in nonatopic subjects: results from the European Respiratory Health Survey. J Allergy Clin Immunol 1999, I 04:30 I-4.

29. Vignola AM, Chanez P, Godard P, Bousquet J: Relationship between rhinitis and asthma. Allergy 1998, 53:833-9.

30. Bousquet J: Allergic Rhinitis and Its Impact on Asthma. J Allergy Clin Immunol 200I, I 08(Suppl 5): |47-334.

31. Passalacqua G, Ciprandi G, Canonica GW: United airways disease: therapeutic aspects. Thorax 2000, 55(Suppl 2):26-27.

32. Lack G: Pediatric allergic rhinitis and comorbid disorders. J Allergy Clin Immunol 200I, I 08(SuppI I):9-I5.

33. Moller C, Dreborg S, Ferdousi HA, Halken S, Host A, Jacobsen L, Koivikko A, Koller DY, Niggemann B, Norberg LA, Urbanek R, Valovirta $\mathrm{E}$, Wahn U: Pollen immunotherapy reduces the development of asthma in children with seasonal rhinocongiuntivitis (the PAT-study). J Allergy Clin Immunol 2002, I 09:25 I-6.

34. Beckman DB, Grammer LC: Pharmacotherapy to prevent the complications of allergic rhinitis. Allergy Asthma Proc 1999, 20:215-23.

35. Skoner DP: Complications of allergic rhinitis. J Allergy Clin Immunol 2000, I05(Suppl 6):605-9. 
36. Rasmussen F, Siersted HC, Lambrechtsen J, Hansen HS, Hansen NG: Impact of airway lability, atopy, and tobacco smoking on the development of asthma-like symptoms in asymptomatic teenagers. The Odense Schoolchild Study. Chest 2000, I 1 7:1330-35.

37. Vesterinen E, Kaprio J, Koskenvuo M: Prospective study of asthma in relation to smoking habits among 14729 adults. Thorax 1988, 43:534-539.

38. Larsson L: Incidence of asthma in Swedish teenagers: relation to sex and smoking habits. Thorax 1995, 50:260-4.

39. Basagana $X$, Sunyer J, Kogevinas M, Zock JP, Duran-Tauleria E, Jarvis $D$, Burney P, Anto JM, European Community Respiratory Health Survey: Socioeconomic status and asthma prevalence in young adults: the European Community Respiratory Health Survey. Am J Epidemiol 2004, 160:178-88.

40. Akerstedt $T$, Fredlund $P$, Gillberg $M$, Jansson B: A prospective study of fatal occupational accidents-relationship to sleeping difficulties and occupational factors. J Sleep Res 2002, I I:69-7I.

4I. Barbe Pericas J, Munoz A, Findley L, Anto JM, Agusti AG: Automobile accidents in patients with sleep apnea syndrome. An epidemiological and mechanistic study. Am J Respir Crit Care Med 1998, 158:18-22.

42. Brown ES, Khan DA, Mahadi S: Psychiatric diagnoses in inner city outpatients with moderate to severe asthma. Int J Psychiatry Med 2000, 30:319-327.

43. Nascimento I, Nardi AE, Valenca AM, Lopes FL, Mezzasalma Ma, Nascentes $R$, Zin WA: Psychiatric disorders in asthmatic outpatients. Psychiatry Res 2002, I 1 0:73-80.

44. Rosero SZ, Zareba W, Moss AJ, Robinson JL, Hajj Ali RH, Locati EH, Benhorin J, Andrews ML: Asthma and the risk of cardiac events in the long QT syndrome. Long QT Syndrome Investigating Group. Am J Cardiol 1999, 84:1406-II.

45. Wilson AM: Are antihistamines useful in managing asthma? Curr Opin Allergy Clin Immunol 2002, 2:53-920.

46. Van Ganse E, Kaufman L, Derde MP, Yernault JC, Delaunois L, Vincken W: Effects of antihistamines in adult asthma: a metaanalysis of clinical trials. Eur Respir J 1997, 10:22 16-24.

47. Holland WW: European Community Atlas of 'Avoidable Death' 1985-89 Oxford: Oxford University Press; 1997.

Publish with Bio Med Central and every scientist can read your work free of charge

"BioMed Central will be the most significant development for disseminating the results of biomedical research in our lifetime. "

Sir Paul Nurse, Cancer Research UK

Your research papers will be:

- available free of charge to the entire biomedical community

- peer reviewed and published immediately upon acceptance

- cited in PubMed and archived on PubMed Central

- yours - you keep the copyright

Submit your manuscript here:

http://www.biomedcentral.com/info/publishing_adv.asp
BiolMedcentral 